locate them, as well as to determine their light. A wedge inserted in the field of a transit instrument will permit the determination of the light of each star observed without interfering with the other portion of the observation. If the stars are all bright, time may be saved by dispensing with the thin portion of the wedge. In equatorial observations of asteroids the light may be measured photometrically with little additional expenditure of time. Perhaps the most useful application would be in the observation of zones. When the stars are 'somewhat scattered it would often happen that their light might be measured without any loss of time. By this instrument another field of usefulness is opened for the form of horizontal telescope advocated at a former meeting of this Academy (Proc. Amer. Acad. XVI. 364). Very perfect definition would not be required, since it would affect all the stars equally. To an amateur who would regard the complexity of an instrument as a serious objection to it, a means is now afforded of easily reducing his estimates of magnitude to an absolute system, and thus rendering them of real value.

\section{ELECTRICITY ON PIKE'S PEAK}

THE following extracts relative to electricity, from Pike's Peak Monthly Abstract Journals, have been very kindly forwarded to us by General Hazen, the chief of the U.S. Signal Service, in accordance with a request made by us; we believe their publication will prove useful :-

November 23, 1873.-Atmospheric electricity manifested itself when line was broken by a crackling sound when binding screws were touched, and bright sparks drawn when storepipe was touched by my fingers.

December 7, 1873. - While line was broken $I$ heard relay working ; thinking line had been repaired, I hastened to adjust; received a severe shock, which convinced me that something stronger than our battery had charged the wire. Instrument cut out and lightning arrester screwed closer; in a few minutes a continuous stream of electricity passed between the two plates of the arrester with a loud noise, resembling that produced by a child's rattle; the fluid passed not in sparks, but in five or six continuous streams of light, as thick as a pencil lead, for two or three minutes at a time, with short intervals between; this continued for over an hour.

December I I, I873.- On retiring I accidentally touched my drawers with two fingers of my hand, and drew two sparks from them. This is a common phenomenon after a snow-storm.

Fanuary 12, 1874.-Electric shocks.

Fanuary 24, I874.- Received electric shock when opening stove door; as usual, it was not repeated.

February 25, 1874.--.Same as January 24.

May 11, 1874.-During the entire day severe shocks were felt by any one touching the wire, and, the line being open, I could make plain signals with the key for abont ten minutes.

May 20, I874.- p.m., report could not be sent on account of atmospheric electricity (a thunder-storm).

May 21, 1874.-A flash of fire about two feet long leaped from arrester into the office, illuminating the rooms.

May 24, 1874. -A heavy thunder-storm passed slowly and directly over the peak; large sparks passed constantly through the arrester, while a strange crackling of the snow could be heard at times. While making the 2 p.m. observation, I heard the snow crackle as above mentioned, and felt at the same time on both temples, directly below the brass buttons of my cap, a pain as if from a slight burn. Putting up my hands, there was a sharp crack, and all pain had disappeared.

May 29, x 874.-At 6.20 a terrific storm commenced; blinding flashes of fire came into bath-rooms from the lightning-arrester and stoves; loud reports followed in rapid succession.

Fuly $x, 1874 .-A$ party of visitors were caught in a thunder storm not far from the summit, and all state that they experienced peculiar burning sensations on face and hands, and heard a hissing sound proceeding from hair and whiskers.

Fuly 9, 1874.- - Heavy thunder-storm; large sparks passed through the arrester during its continuance. $\mathrm{Mr}$. Copley telegraphed me this forenoon that he twice got knocked down, while repairing the line, by electric shocks.

Fuly I4, 1874 . - Thunder storm; lightning in beginning very severe. I received a very painful shock while working over the line by my fingers accidentally touching the metal of the key.

$\mathcal{F}^{\prime} l_{1} 15,1874$. - Thunder heard in the distance throughout the evening, while strong ground currents passed through the arrester.

Fuly 16, 1874.-Severe thunder-storm; sharp flashes and retorts came through the arrester to the terror of several lady visitors. Outside the building the electric effects were still more startling. The strange crackling of the hail mentioned before was again heard, and at the same time my whiskers became strongly electrified and repellant, and gave quite audible hissing sounds. In spite of the cap I wore my scalp appeared to be pricked with hundreds of red hot needles, and a burning sensation was felt on hands and face; several of the visitors who were outside had the same experience. A large dog who had followed his master out-doors became terrified, and made for the door with a pitiful howl. Lightning was seen in all directions in the evening, and ground currents passed incessantly through the arrester.

Fuly I9, 1874. - A severe thunderstorm passed close over the Peak between I.30 and 2.30 p.m.; lightning struck wire between 2 nd and 3 rd poles from the louse; for a moment the wire resembled a rope of fire and vibrated violently for some inutes after the discharge-no damage done. Frequent loud discharges took place along the ground-wire between it and the rocks on which it rests. Hair and whiskers of anyone outdoors were electrified by each discharge.

$\mathcal{F}$ uly 21, 1874.-Heaviest thunderstorm of the season to-day; lightning terrific; constant crackling of fallen hail and peculiar clattering of the rocks as if shaken by subterranean convulsions, indicated the highly electrified state of the summit.

August 2, 1874.-I was obliged to keep the telegraph instruments cut out during the greater part of the day.

August 3, 1874. - The lightning rendered the line almost useless the entire afternoon; I got severely shocked when sending my report.

August 13, 1874. - Seventeen visitors to day; some of them made the ascent during a severe thunderstorm, and were much alarmed by the effects of the electricity upon their hair, one of them declared that his hair stood up so stiffly as to lift off his hat!

October $5, \times 874 .-$ Severe thunderstorm below summit in after. noon, observers severely shocked whilst calling Fenton at lower station.

May 22, 1875.-During storms to-day (hail and snow) electricity quite strong.

May 23, 1875.-Electricity strong at intervals during day and night.

May 24, 1875.-Hail from 3.55 p.m. till midnight, accompanied by very strong electricity, decreasing and increasing in intensity, a notable fact in all hail-storms.

May 25, 1875.-Electricity has shown itself nearly all day with variable force (hail frequent during the day)

May 29, 1875.- Hail about midday accompanied by electricity. In all our hailstorms the fall of hail entirely ceases for about a half a minute, following a heavy electric discharge, and the hailfall is considerably heavier for some little time following the discharge than before.

Fuly 5, 1875.-Terrible electric storm in afternoon, at first its effects were felt only by the line, but about $2 \mathrm{p.m}$. its presence was evident everywhere on the summit; a constant stream of flame from the arrester; a constant crackling noise heard out of doors as though made by small pistols.

May II, 1876.-During hailstorm at 7.30 I was compelled to cut out the wires owing to intensity, this I attempted with ungloved hand, and learned a lesson that was an impressive one luckily I escaped with a slightly bruised head and a fearful scare.

May 25, 1874.-D During a thunderstorm the wire outside, at two or three places, kept up a peculiar singing noise, resembling the singing cricket. I have previously noticed that the singing noise is never heard except when the atmosphere is very damp, and rain, hail, or snow is falling.

Fune I6, I876. - At $5.20 \mathrm{p}$. m., as I was sitting on a rock near the monument, on the eastern edge of the summit, a blinding flash of lightning darted from a cloud seemingly not more than 500 feet north-east of me, and was accompanied by a sharp, quick, deafening report, and at the same time I felt the electricity dart through my entire person, jerking my extremities together as though by a most violent convulion, and leaving tingling sensations in them for a quarter of an hour afterwards. Straine, who was sowing wood in the shed at the time received a similarly violent shock, and says that a ball of lightning ap- 
peared to pass through the store-room and wood-shed in which he was working, leaving behind a strong sulphurous smell.

Fuly 13, 1876.-Singing on the wire. It also seemed to come from the instrument shelter and the house, as well as from the wire. Thunder loud and continuous during the afternoon.

Fuly 23, 1876. - The anemometer stopped working on account of the electric storm. Privates Straine and O'Keefe were shocked while trying to fix it, so that they had to give it up until the storm had subsided somewhat.

August 18, 1876.-A beautiful phenomenon was observed by myself, Private Greenwell, and four visitors. The peculiar singing noise (or sizzing noise) was heard again, always before in day, but this time at night, but the line for an eighth of a mile was distinctly outlined in brilliant light which was thrown out from the wire in beautiful scintillations. Near us we could observe these little jets of flame very plainly. They were invariably in the shape of a quadrant, and the rays concentrated at the surface of the line in a small mass about the size of a currant, which had a bluish tinge. These little quadrants of light were constantly jumping from one point of the line to another, now pointing in one direction then in another. There was no heat to this light, and when I touched the wire I could only feel the slightest tingling sensation. Not only was the wire outlined in this manner, but every exposed metallic point and surface was similarly tipped or covered. The cups of the anemometer appeared as four balls of fire revolving slowly round a common centre. The wind vane was outlined with the same phosphorescent light, and one of the visitors was very much alarmed by sparks, which were plainly visible in his hair, though none appeared in ours. At the time of this phenomena snow was falling. day.

March 27, 1877.- Singing noise heard upon the wire to-

May 12, 1877.-Hailstorm, accompanied by intense electricity. May 24, 1877.- Sergeant Hobbs and Private Greenwell received severe shocks during the day.

August 6, 1877.-Intense electricity; all metal objects were tipped with sparks.

November 25, I877.--Snow-storm all day attended by intense electricity, which could be heard crackling in a person's hair continuously, although no reports of thunder were heard.

December 26, 1877. - The atmospheric electricity was very intense during the day, and at times wonld crackle on various objects in the room.

Tanwary 25, I878.- Several thunderstorms occurred in the strrounding parks and gulches. The electricity on the summit was very intense, causing a continuous snapping of the lightning arrester.

May 12, 1878.-A snow-storm commenced during the night, and at $\mathrm{I}$ p.m. was drifting furiously by a rising gale. The electricity varied with wind-gusts, and was so intense at times as to render our position exceedingly dangerous. The telegraph wires were cut out, but violent sparks would still jump six inches between the disconnected windows. One violent discharge seemed to have occurred in the chimney, for a terrible commotion was caused in the soot and ashes.

May 24, 1878.-At 8 p.m. snow commenced, attended with severe electricity, lasting for an hour. The wires had to be cut out and parted, and a vivid glaring was continuous in the windows. A lamp set in the north window would, with its flame, cast a shadow on the opposite wall for several seconds.

Fuly I, 1878.-During afternoon sleet fell, accompanied by intense electricity. At 3.20 a violent explosion occurred in the room, near the stove, scattering the wood and knocking down the stove-pipe.

April I0, I879.- The telegraph wire heavily charged with a ground current of electricity this evening, and it was with difficulty that signal was transmitted. The current at times was entirely reversed.

Fune $\mathrm{I} 6$, 1879. - Light sleet, accompanied by thunder. Only a few peals were heard, when it gave way to a strong steady current over the wire, and for twenty minutes one of those electric storms peculiar and common to Pike's Peak prevailed. A queer hissing sound from the telegraph line, the wind-vane post and other posts standing in a deep snow $\bullet$ drift near by. I stepped out to view the phenomenon, but was not standing in the snowdrift long, when the same buzz started from the top of my head, my hair became restless, and feeling a strange creeping sensation all over my body, I made quick steps for the station; once inside upon the dry floor, the effects soon left me. After getting inside I opened the telegraph key, and found a continuous bright spark passing between the key and the anvil, even when they were separated one-eighth of an inch; and by putting two thicknesses of writing-paper in this space, it was scorched, and perforated by numerous burnt holes. By accident I completed the circuit with both hands, when I received a shock that sent me back on the floor.

Fune 29, 1879.-Thunder-storm (very severe), II.IO to II.30 a.m., during which time a bolt passed through the arrester with a report exceeding that of a rifle, and threw sparks all over the office. The suddenness and violence of the shock stunned me, so that it was a little while before I could realise what had happened.

August I I, 1879.-During passage of a thunder-storm over the Peak a great amount of atmospheric electricity was manifested.

August 12, 1879.-Heavy snow and sleet began falling at 5.30 p.m. ; at 5.40 p.m. a ball of lightning went through the arrester with the report of a rifle, throwing a ball of fire across the room against the stove and tin sheathing; the wood-packers, Messrs. Wade and McDonald, had taken refuge in the station for a few minutes, but concluded immediately that this was rather an utcomfortable place during a storm, and left immediately; their dog however was far in advance in seeking shelter outside. $\mathrm{Mr}$. Wade declared that the lightning struck him in his feet and legs. At 6 p.m. the lightning struck the wire and building at the north end, where the wires come through the window and arrester with a crash equal to any 40-pounder. It burned every one of the four wires coming in at the window into small pieces, throwing them with great force in every direction, and filled the room with smoke from the burned gutta-percha insulation; the windowsash was splintered on the outside, one pane of glass broken, and another coated with melted copper. The anemometer wires were also burned up and the dial of the anemometer burned and blown to pieces. Private Sweeny was about deaf for some time afterwards. One piece of the wire was thrown with such force that when it struck the barometer three feet distant it was wound around it, without, however, doing any damage to the barometer.

Fuly 2, 1880.- Line worked poorly on account of storm, each flash of lightning causing the instrument to be thrown out of adjustment; the signals at midnight were got off with great difficulty.

Fuly 19, 1880.-Atmospheric electricity quite prevalent during the evening.

Fuly $2 \mathrm{r}, 188 \mathrm{o}$.- - Hail in afternoon and night, accompanied by heavy flashes of lightning which played around the arrester, and exploded with great force.

Fuly 23, 1880.- Hail, rain and snow during the day; ended at $5.40 \mathrm{p} . \mathrm{m}$. Intense ground currents during prevalence of storm.

Fune 23, 188r. - A light fall of hail, accompanied by terrific flashes of lightning, which snapped on the lightning arrester, and exploded with great violence.

7 fuly 4, 1881.- During the progress of the rain-storm it was accompanied by the heaviest discharges of lightning and thunder that I ever witnessed in all my experience at this station. The lightning snapped on the arrester and exploded with great violence in the office. Several times during the evening $I$ was certain that the station building would be struck and demolished, as the lightning was almost continuous.

August 21, 1881. - Heavy hail began falling at I2.30 p.m., continued at intervals until $4.15 \mathrm{p} . \mathrm{m}$., when it ceased. The hail was accompanied with the heaviest discharges of lightning that I ever witnessed in all my experience at this station. It was impossible to remain in the office during the progress of the hailstorm, as the lightning was almost continuous, and snapped and exploded in all directions, so that I was compelled to retreat to the kitchen for safety. The south-west portion of the stationbuilding was struck by lightning, but no damage of any consequence was done, nor was the station-building impaired by the shock. The lightning arrester and ground wires were badly damaged, but the worst feature of the storms was the fact that both the station and extra barometers were also struck, and the cisterns of both cracked.

During the storm a shepherd was killed by lightning, and when found was stripped of his clothing and boots; he had taken refuge under a tree. 